\title{
Restoration of the Severely Resorbed Maxilla and Mandible using the Multicup Denture
}

\author{
${ }^{1}$ Chandrakala V, ${ }^{2}$ Nandeeshwar DB \\ ${ }^{1}$ Senior Lecturer, Department of Prosthodontics, KLE Society's Institute of Dental Sciences, Bengaluru, Karnataka, India \\ ${ }^{2}$ Professor and Head, Department of Prosthodontics, Bapuji Dental College and Hospital, Davangere, Karnataka, India
}

Correspondence: Chandrakala V, Senior Lecturer, Department of Prosthodontics, KLE Society's Institute of Dental Sciences Yeshwanthpur Suburb, Bengaluru-22, Karnataka, India, e-mail: drchandra10@gmail.com

\section{ABSTRACT}

A basic concern of edentulous patients is retention of their dentures. This has led to considerable experimentation and research in efforts to perfect dentures that compensate for the loss of natural teeth. The use of multiple miniature suction cups made from a soft material lining the denture satisfies the requirements of retention and stability. A technique describing the fabrication of a maxillary and mandibular multicup dentures which are more beneficial than conventional complete dentures is discussed below with case report.

Keywords: Suction cup, Denture retention, Soft denture liner.

\section{INTRODUCTION}

For millions of edentulous patients, complicating factors, such as high surgical risk, underlying pathology, compromised blood supply, economics, or simply unwillingness on the part of the patient to undergo any surgery, may have precluded improvement of their situation by grafting and/or placement of dental implants. In such patients, use of prosthesis lined with a permanent soft liner, containing multiple small suction cups covering the basal seat area can be successful treatment. ${ }^{1}$

\section{HISTORY}

The concept of multiple small suction cups incorporated into the intaglio surface of a denture is not a revolutionary idea. Incredibly, three early US patents, two in 1885 and one in 1907, were granted for complete denture designs based on such a concept. ${ }^{9}$

With more than 20 patents to his credit, Dr Arthur C Jermyn, originally from Rochester, New York, resurrected the idea of suction cup-retained dentures with research that began in 1952. By 1963, after experimenting with many polymer materials and suction cup designs, he finalized his technique. He settled on a high molecular weight dimethylpolysilane because of its physical properties, ease of handling and survivability. This material, coupled with Dr Jermyn's unique suction cup design, has been used for decades to produce dentures with significantly enhanced retention and stability. ${ }^{2-10}$

\section{CASE REPORT}

A 35-year-old female patient was reported to the department, for replacement of her unsatisfied complete dentures with history of extraction of her teeth due to periodontal problems 6 years back. Since then, patient was a denture wearer but was unhappy by her retention and esthetics. Her intraoral examination (Fig. 1) revealed severely resorbed maxilla (Type B: American college of prosthodontics classification) and mandible (type 3-American College of Prosthodontics Classification). Also, because of her fear and low economic condition she was unwilling to undergo surgical intervention to
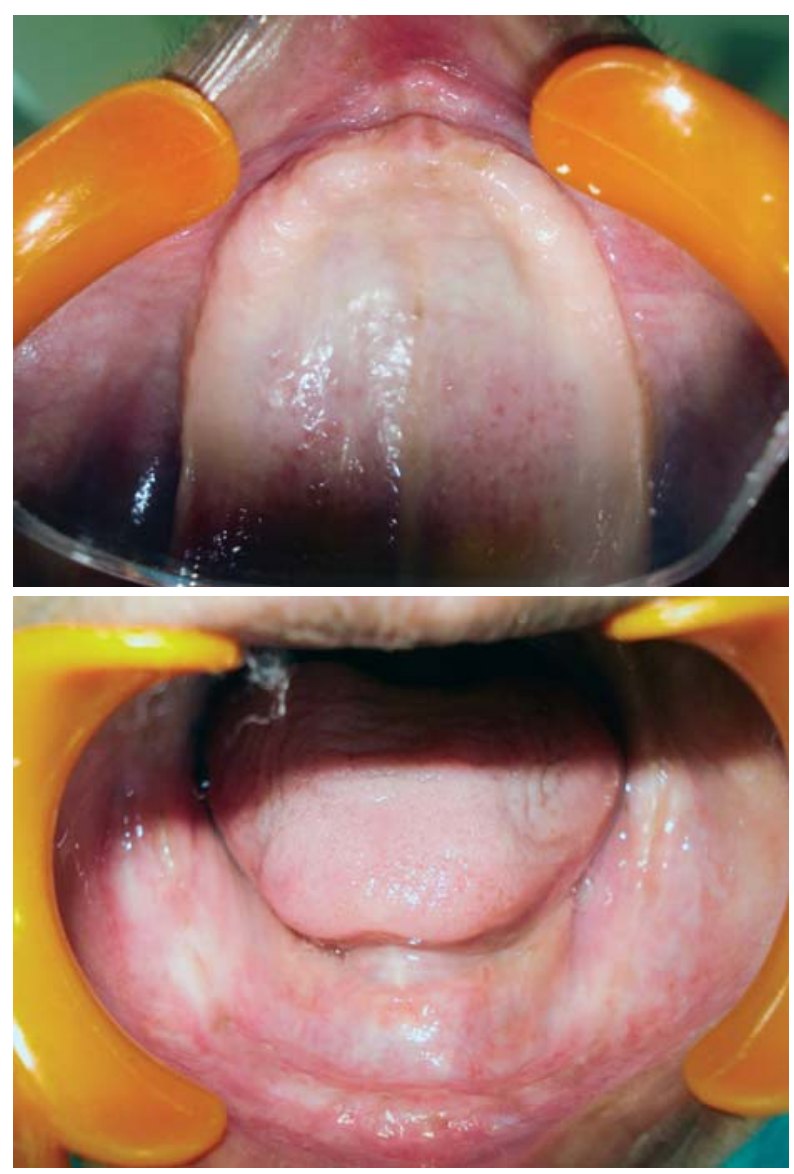

Fig. 1: Severely resorbed maxilla and mandible 
facilitate prosthesis retention. So considering these facts, maxillary and mandibular multicup dentures were planned.

\section{PROCEDURES}

1. Impressions of maxillary and mandibular edentulous arches were made using irreversible hydrocolloid impression material. Border molding, final impression and jaw relations procedures were carried out. Dentures were fabricated to the trial denture stage.

2. The maxillary and mandibular trial dentures were waxed up, flasked and dewaxed. The heat cure acrylic resin was packed and after curing process, the flasks were deflasked; the dentures were remounted, finished and polished.

3. Precise holes were prepared in the duplicated master cast using cup-shaped stainless steel bur (No. 014, Mendesco Company, Mumbai) and straight hand piece (Figs 2 and 3). The holes were $2 \mathrm{~mm}$ in diameter, approximately $1 \mathrm{~mm}$ deep, and had walls with a $12.5^{\circ}$ taper (Fig. 4). They were spaced 1 to $1.5 \mathrm{~mm}$ apart, and prepared perpendicular to the palatal and ridge surfaces. They were not prepared over frenum attachments or within $2 \mathrm{~mm}$ of the denture borders. At least 200 holes for a maxillary cast and 150 for a mandibular cast must be drilled. The holes were drilled perpendicular to the mucosal surface so that the hole core was not broken.

4. The permanent soft liners (GC Dental Products Corp) were then added to processed complete dentures by creating space for the material in the base prior to making reline impressions (Fig. 5). The liner space was prepared $2 \mathrm{~mm}$ short of all denture borders with $90^{\circ}$ butt joint margins and 1 to $2 \mathrm{~mm}$ deep. Excess material from the borders were removed (Fig. 4).
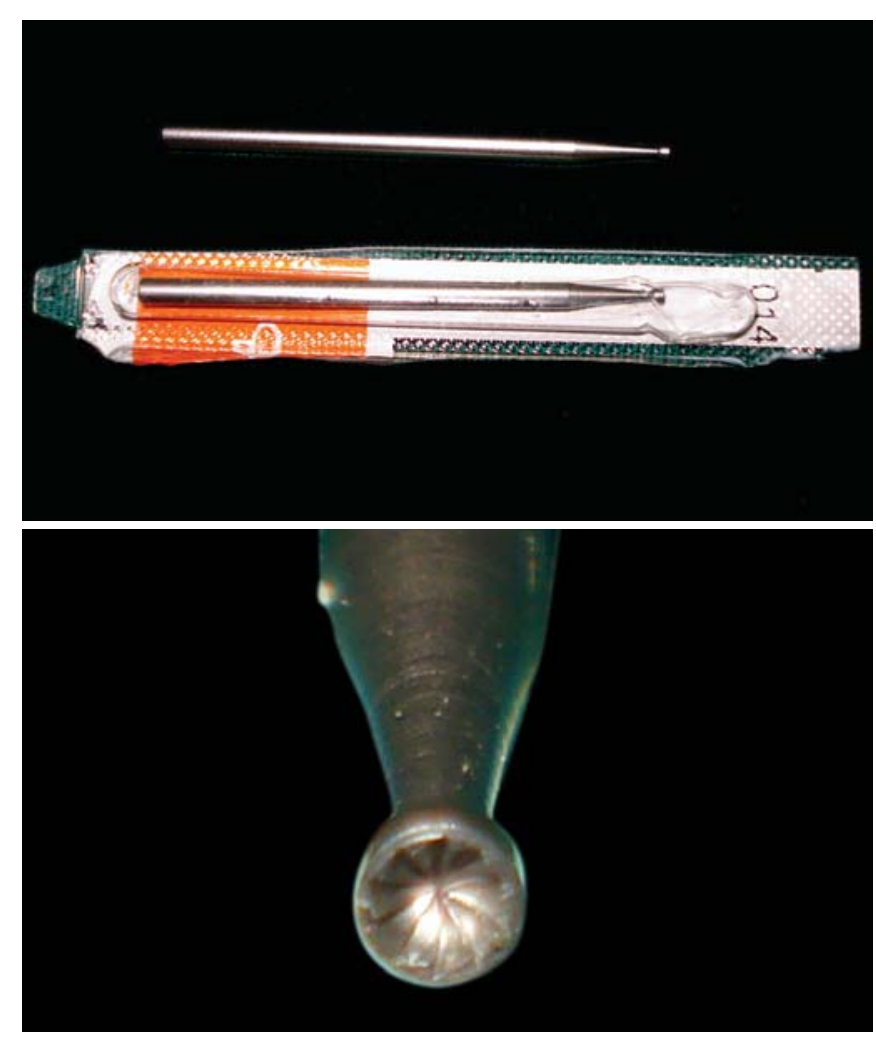

Fig. 2: Stainless steel bur
5. Multicup maxillary and mandibular complete dentures were inserted (Figs 6 to 9). Follow-up was done at 1 day, 1 week, 2 weeks and 1 month intervals. The basal tissues of the patient showed expected shallow imprints of the suction cups but no signs of inflammation. Denture cleanser, which is not strong and do not cause breakdown of delicate suction cups, was recommended. The patient was more satisfied, comfortable and happy with the new dentures.

\section{CONCLUSION}

A simple technique for enhancing the retention and stability of dentures has been described. The multicup denture liner was used to enhance retention, stability and comfort for complete denture wearers, particularly for those with significant resorption
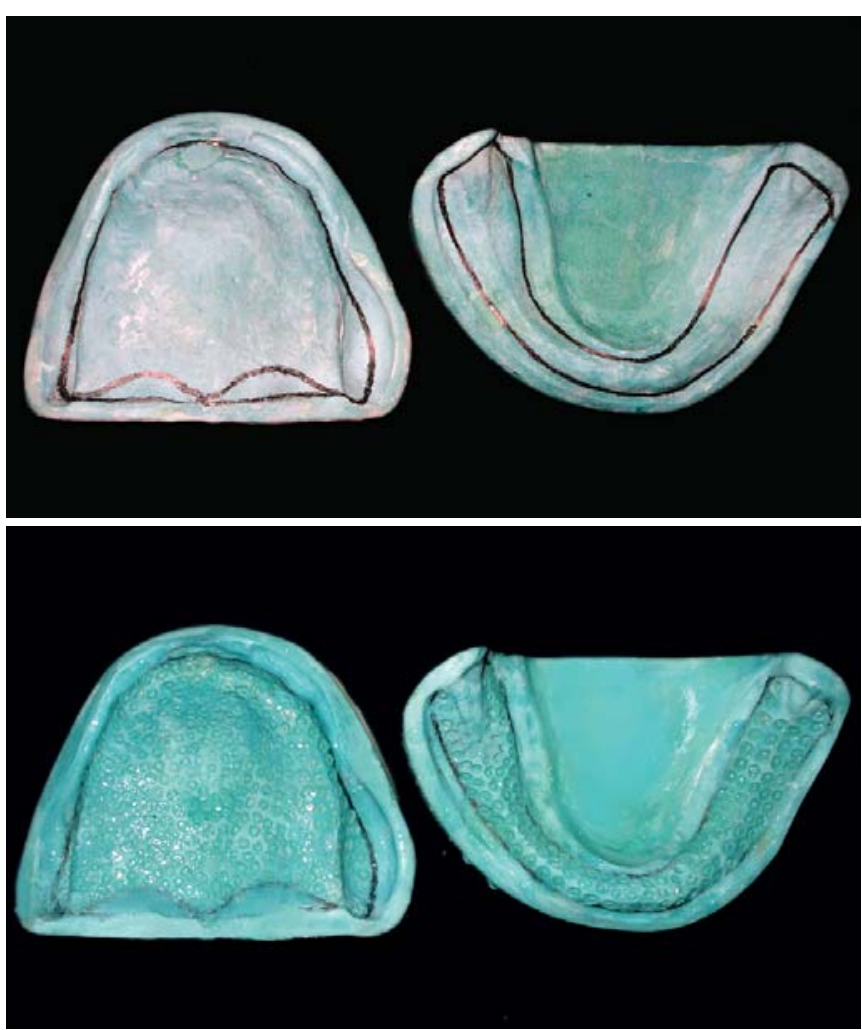

Fig. 3: Precise holes prepared on master cast

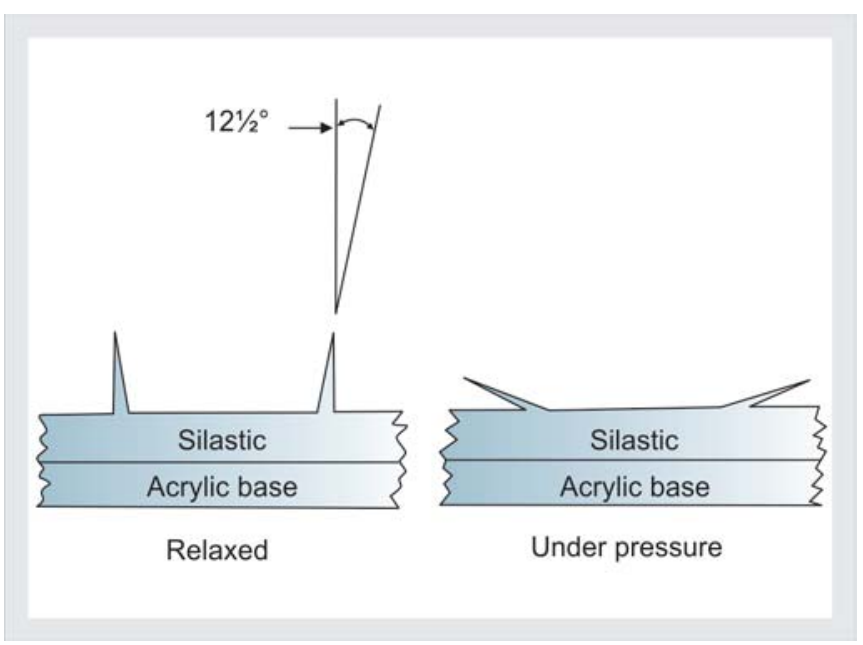

Fig. 4: Soft liner removed $2 \mathrm{~mm}$ short of the sulcus 

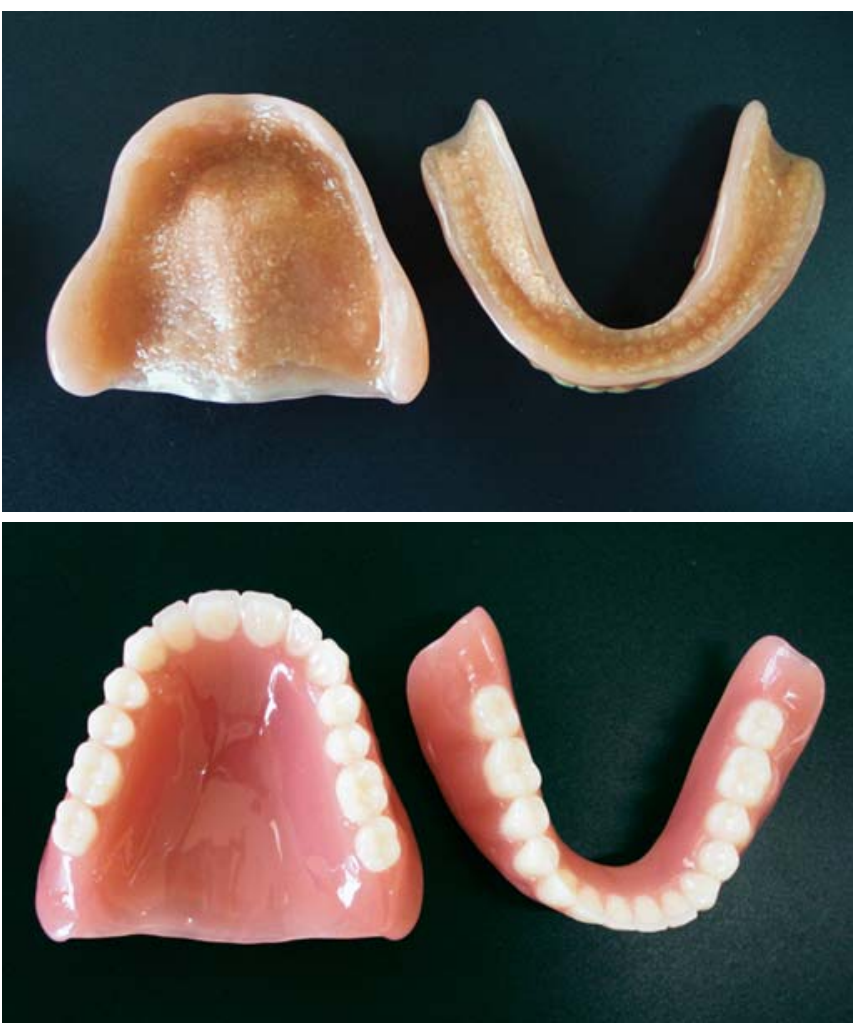

Fig. 5: Holes prepared with $12.5^{\circ}$ taper
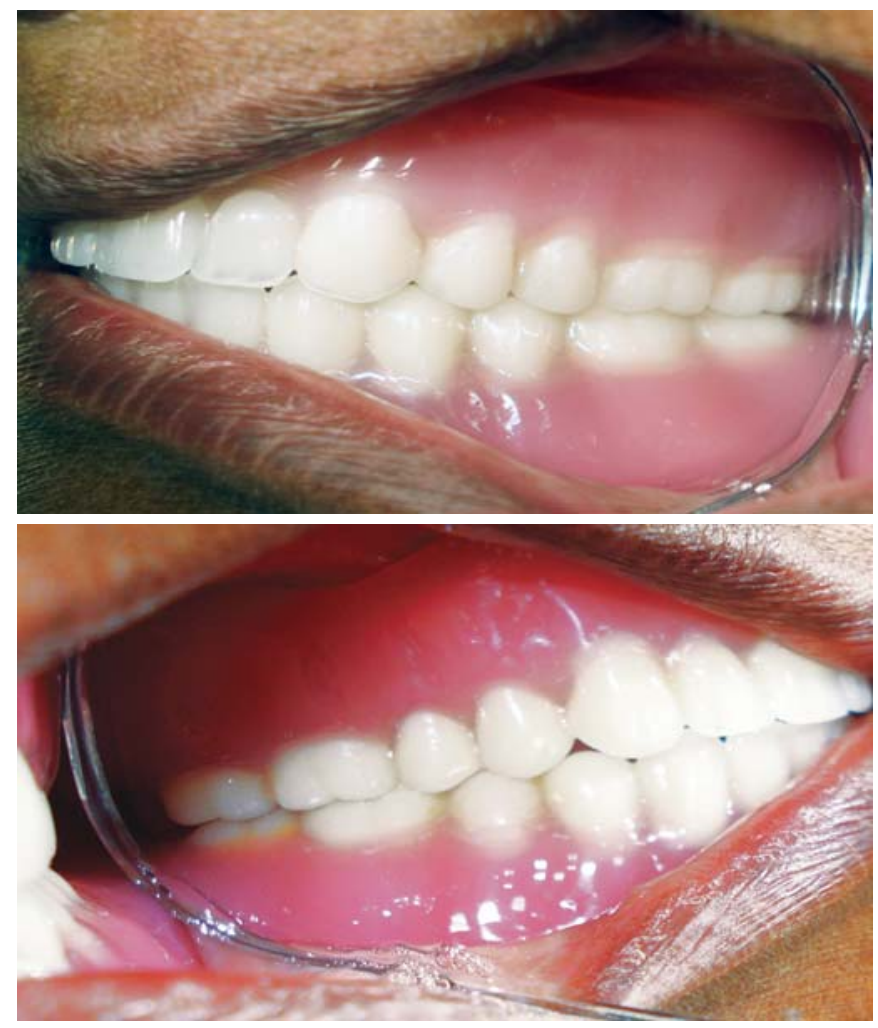

Fig. 6: Multicup denture in occlusion

of their alveolar ridges. On the contrary, the exacting multicup technique requires accurate impressions. A large number of small suction cups formed from a soft permanent soft liner serve to grip the oral tissues without causing any pathosis. The tissues tend to assume the negative form of these cups, but they return to normal when the dentures are removed. The tissues appear
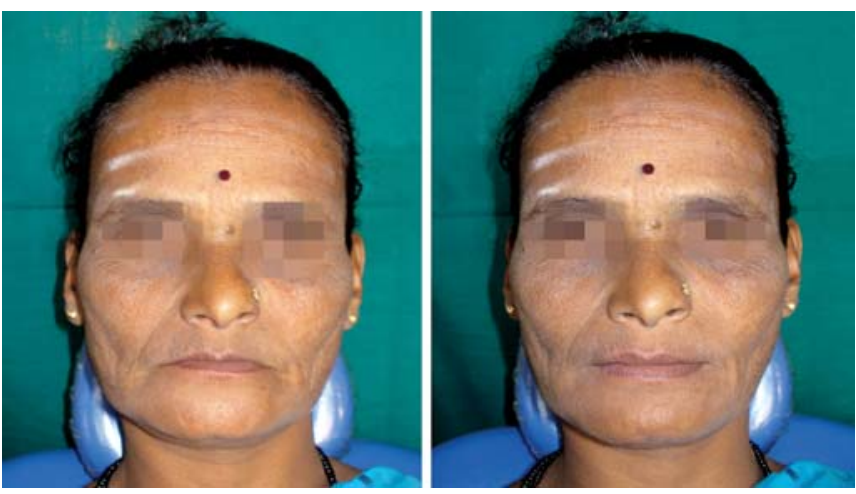

Fig. 7: Frontal view without and with complete dentures
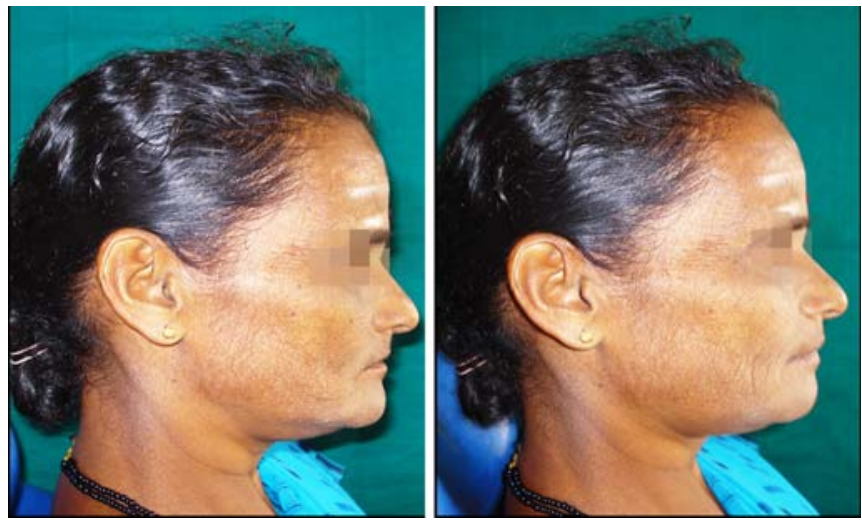

Fig. 8: Lateral view without and with complete dentures
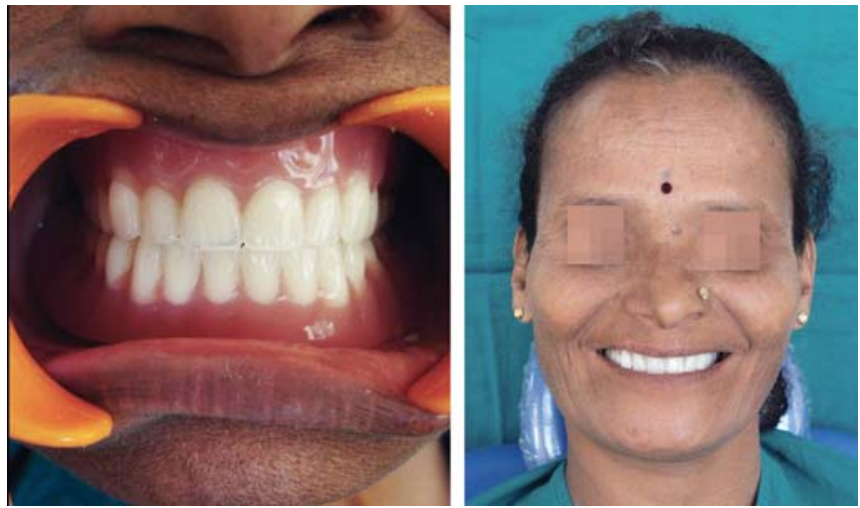

Fig. 9: Happy and satisfied patent

normally moist, pink, and healthy. This technique solves many of the physiologic and psychologic problems associated with denture wearing, but this is no panacea for all denture troubles. When properly done, the use of these multiple suction cups can make the difference between success and failure. The multicup denture liner offered a viable alternative to enhance denture retention when patient desired and was unwilling for other treatment modalities.

\section{REFERENCES}

1. Engelmeier RL, Gonzalez ML, Harb M. Restoration of the severely compromised maxilla using the multi-cup denture. J Prosthodont 2008;17:41-46.

2. Jermyn AC. Multiple suction cup dentures. J Prosthet Dent 1967;18:316-25. 
3. Mc Garry TJ, Nimmo A, Skiba JF, et al. Classification system for complete edentulism. The American college of prosthodontics. J Prosthodont 1999;8:27-39.

4. Mc Garry TJ, Nimmo A, Skiba JF, et al. Classification system for partial edentulism. J Prosthodont 2002;11:181-93.

5. Whyman E, Valbuena L. The valve principle in denture retention, making palateless dentures possible. Dent Items Interest 1933;55:206-11.
6. Misch CE. Contemporary implant dentistry (2nd ed). St. Louis: MO, Mosby 1999;pp 3-12.

7. Chase WW. Tissue conditioning utilizing dynamic adaptive stress. J Pros Dent 1961;11:804-15.

8. Pound E. Conditioning of denture patients. JADA 1962;64: 461-68.

9. Morgan GW. Patent \#869,191, United States Patent Office, Washington, DC.

10. A tribute to Dr Arthur C Jermyn. Oral Implantol 1995;21:262. 